\title{
Entegre Bilgi Sistemi Modeli Geliştirilmesi: DataOCEAN@
}

\author{
Egnar ÖZDİKILİLER ${ }^{1}$, Çiğdem GÖKSEL ${ }^{2 *}$ \\ ${ }^{1}$ İstanbul Teknik Üniversitesi, Uydu Haberleşmesi ve Uzaktan Algılama ArGe Merkezi, İstanbul \\ (ozdikililer@itu.edu.tr) ORCID ID 0000 - 0002 - 9042 - 2324 \\ ${ }^{2}$ İstanbul Teknik Üniversitesi, İnşaat Fakültesi, Geomatik Mühendisliği Bölümü, İstanbul \\ (goksel@itu.edu.tr) ORCID ID 0000-0001-8480-1435
}

\begin{abstract}
Öz
Günümüzde veri çeşitliliğinin artması, özellikle konumsal verinin eklenmesiyle, düzenli ve güçlü sistem tasarımı gereksinimi giderek daha önemli hale gelmiştir. Merkezi erişim sağlayan, Coğrafi Bilgi Sistemlerini de kapsayan, yeni nesil bilişim sistemleri tasarlanarak kullanım yaygınlaştırılmıştır. $\mathrm{Bu}$ durum, özellikle kurumlar arası veri paylaşımı ve farklı yapıdaki, sistemler arasındaki entegrasyon çalışmalarını hızlandırmıştır. $\mathrm{Bu}$ nedenle, merkezi erişim amaçlayan sistem tasarım çalışmaları artmış, veri erişimi de web servislerinin yaygın olarak kullanıması ile kolaylaşmıştır. Bu çalışmada, dağıtık sistemler için; hızlı, doğru ve güvenilir bilgiye erişimde kullanılabilecek yeni bir entegre bilgi sistemi modeli tasarlanmıştır. Tasarlanan model; birlikte çalışabilirlik ilkelerini koruyan, hibrid yapı temelli, birden fazla sistemi barındıran, entegrasyonu web servisleri aracılığı ile sağlayarak, çok yönlü veri akışına olanak tanımaktadır.

Çalışmada tasarlanan model (DataOCEAN) ve sistem prototipi, Servis Yönelimli (SOA) yapıyı temel alan ve Nesne Yönelimli mimari (OOA) yapısına benzerlikler taşımaktadır. Kullanılan yapı, MVC mimari tabanlı yazılmıştır ve özgün bir çalışmadır. REST yaklaşımı ile tasarlanmış, RESTful ve SOAP servis mimarilerine ilişkin web servisleri hazırlanmış, sistemin yönetim panelinin içereceği alanlar yazılmış ve test edilmiştir. Uygulama dili olarak PHP (Hypertext Preprocessor) tercih edilmiş, mekansal veri gösterimi için GoogleMAPs kullanılmıştır.
\end{abstract}

Anahtar Kelimeler: Veri Entegrasyonu, Coğrafi Bilgi Sistemleri, Web Servisleri, Mekansal Veri

\section{Design a Model for Integrated Information Systems: DataOCEAN@}

\begin{abstract}
Nowadays, with the increase in the variety and volumes of data, in addition spatial data, the need for a reliable, systematic and powerful system design has increasingly become more important. Next generation information systems facilitating central access, including Geographical Information Systems, were designed and their use has become widespread. This has particularly accelerated data exchange between institutions and integration work between systems with different structures. Thus, system design works aiming at providing central access have increased, and data access has become easier thanks to the spread of web services.

In the context of this study, a new integrated information system model was designed to be used in providing access to fast, accurate and reliable information for distributed systems. This model protects the principles of interoperability, is based on a hybrid structure, accommodates multiple systems and enables multifaceted data flow by providing integration through web services.

The model and system prototype (DataOCEANC) is based on service oriented architecture (SOA) while it shares similarities with object oriented architecture (OOA). The framework used in the design is an original

\footnotetext{
* Sorumlu Yazar

Egnar Özdikililer. "Entegre Bilgi Sistemi Modeli Geliştirilmesi: DataOCEANC” Doktora Tezi, Yürütücü: Doç.Dr. Çiğdem Göksel, İTÜ, Bilişim Enstitüsü
} 
work based on model-view-controller architecture. It was designed using REST (Representational State Transfer) style. Web services in relation to RESTful and SOAP (Simple Object Access Protocol) service architectures were prepared; areas to be included in the management panel of the system were written and tested. PHP (Hypertext Preprocessor) was chosen as application language while using GoogleMAPs for spatial data representation.

Keywords: Data Integration, Geographic Information Systems, Web Services, Spatial Data

\section{GÍRİs}

Günümüzde, bilişim teknolojisi ile bilgiye ulaşım ve bilgiyi kullanabilme gücü giderek artmaktadır. Merkezi ve yerel yönetimler ile bilgiyi kullanan çok çeşitli iş alanında var olan kurum ve kuruluşlar, farklı amaçla kurgulanmış, aynı ve/veya yüksek benzerlikte verileri içeren Coğrafi Bilgi Sistemlerini kullanarak hizmet vermektedir. Her bir kurum, sistem yapısını özgün ve kendi ihtiyaçları doğrultusunda tasarlamaktadır. Bu durumun, kurumların bilgi sistemlerinin iç işleyişinde kolaylık sağlayacağı düşünülse de diğer bilgi sistemlerinden soyutlanarak yapılandırılmış özgün bir bilgi sisteminde çalışmanın dezavantajları olmaktadır. Kurumlar kendi ürettikleri verileri ve farklı kurumların ürettiği verileri kendi bilgi sistemleri içinde tutmaktadır. Bu çok veri, giderek sistemin yoğunlaşmasına ve zamanla güncelliğini de yitirerek veri tutarsızlığına yol açmaktadır.

Durdurulamayan boyuttaki veri artışı, veri kirliliğine ve veri kalitesinin düşmesine neden olmaktadır. Bu durumda ortaya çıkacak olası sorunları azaltmak amaciyla; birlikte çalışabilirlik ilkeleri gözetilerek standartlar oluşturulup, çeşitli uygulamalar yazılarak sistemlerin birbiri ile haberleşmesi sağlanmaktadır.

Kurumlar arası ve kurum içi etkili iletişim için, veriye web ortamından erişim sağlanması bir devrim niteliğindedir. Kurumlar arası veri paylaşımı gereksinimi; "yeni nesil bilgi sistemleri"nin tasarımını ve merkezi tasarım zorunluluğunu ortaya çıkarmıştır (Glatard, 2017; Ghadiri, 2017; AlKiswany, 2017).

"Yeni nesil Entegre Bilgi Sistemleri" içinde platform bağımsız web servisleri önemli bir yer tutmaktadır. "Merkezi Tasarım", verinin, web üzerinden, belli standartlarda bulunduğu, iletilip, işlendiği bir yapıyı belirlemektedir.
$\mathrm{Bu}$ çalışma, nitelikli veri oluşumu, paylaşımı, kullanımı ve web servislerinin sunduğu avantajlar ile, merkezi sistem tasarımı için bir öneridir. $\mathrm{Bu}$ önerinin uygulamas1 da gerçekleştirilmiştir (Özdikililer, 2017).

Geleneksel uygulama mimarilerinin izlenmesi, sistemlerin büyüme hızına yetişmek veya halihazırda kullanılmakta olan yapıları belli bir tasarım mimarisine uyarlamak için zaman problemi ortaya çıkmaktadır. Problemin çözümü için, üst bir yap1 ya da tüm sistemleri içeren bir katman hazırlanmasının, uygun olacağı görüşü ile verinin performans kaybına uğramadan ve iş gücü artışı gerektirmeden, bilgi sistemlerinde entegre edilebilmesi amaçlanmıştır.

$\mathrm{Bu}$ amaca koşut olarak; servis yönelimli ve nesne tabanlı yazılım mimarileri, güvenli veri akışı sağlayan web servisi mantığı ile birleştirildiğinde, ideal entegre yapının ortaya konulabileceği öngörülmüştür. Web servislerinin nesne tabanlı tanımlama yapıs1 ile sisteme tanitılan, her türden sistemi birbiri ile haberleştirebilen bir ara katman mimarisi tasarlanmış ve uygulaması yapılmıştır.

Yazılım mimarilerinin, modern sistemlerin karmaşıklığı, çok hızlı veri artışı, uygulama çeşitliliği, bilişim sistemlerin uygun bölümleme ve düzenlemeler ile ayrı ayrı sistemler olarak değil de, modüler olarak birbiri ile iletişime geçmeleri amaçlanmıştır. İyi bir ürün veya ürünler zinciri kuvvetli bir altyapı mimarisi ile ortaya çıkabilir. Sürekli gelişen ve ihtiyaçları hızla artan bilişim sistemleri birbiri ile performans kayb1 olmaksızın kolaylıkla entegre olmasının sağlanabilmesi bu çalışmanın motivasyonu olmuştur.

\section{HIIPOTEZ VE YÖNTEM}

"DataOCEAN" - Veri Okyanusu olarak adlandırılan modelde, veri kaynakları çok çeşitli platformlarda bulunan, birbirinden farklı zamanda üretilmiş, farklı karakterde ve 
doğrulukta oluşturulmuş sistemlerdir. Sorgulama anında erişilebilir olan, ihtiyaç halinde bağlantı kurulan ve kullanımdan sonra iletişimi kesen, web veri erişim servisleridir. $\mathrm{Bu}$ servisler, yap1 ve ortam değişimlerinden etkilenmeden, kullanılan uygulamaları ve sistemleri entegre etmektedir. DataOCEAN modelinde, web servisleri nesne yönelimli mimariye uygun tanımlanır ve sorgulanırlar. Nesne yönelimli mimari tanımlaması ile yapı ve ortam değişimlerinden etkilenmemeleri sağlanmaktadır. Tanımlama şekli ile lokal sistemde yapılan değişiklikler genel sistemi etkilememektedir. Servis tanımı, OceanLibrary olarak adlandirılan sistem kütüphanesinde yapılmaktadır. Sistemde, kesintisiz veri sorgulama işlemi kütüphanede yer alan web servislerin birbirinin yerini dinamik olarak alması ile sağlanmaktadır.

Kesintisiz, sürekli veri iletişiminde DataOCEAN sisteminde bir türden veriye ulaşmak için birden fazla ve farklı konumlarda bulunan servislerin entegre edilmesi ile sağlanmaktadır. Data Ocean modelinde, yapısal değişiminin veya güncelleme ihtiyacının oluşması, hatta sürekli hale gelmesi, sistem bütünlüğünü veya çalışmasını etkilememektedir.

Sistemin tasarımında, Servis Yönelimli Mimari (SOA) (Krafzig, 2005; Söderström, 2007; Bahree,2007) yap1 kullanılmış, yararlanılan web servislerin yapısı MVC (Model-View-Controler) mimarisi ile, REST (Representational State Transfer) (Fielding, 2000) kullanılarak ve SOAP (Simple Object Access Protocol) Basit Nesne Erişim Protokolü yaklaşımı temel alınarak kodlanmıştır. Web servislerin yazılım katmanı PHP(PHP: Hypertext Preprocessor) ile yazılmış ve veritabanı olarak SQLite MemoDB kullanılmıştır.

DataOCEAN sistemi tasarlanırken veri havuzundan nitelikli olan veriye hızlı erişim hedeflenmiştir. Çalışmada, dağıtık sistemler arası merkezi veri erişimi ve entegrasyon sorununa optimum bir çözüm getirilerek, yazılım süresi azaltılarak kullanım kolaylığı sağlanmıştır (Özdikililer, 2017).

\subsection{DataOCEAN Sistem Modeli}

DataOCEAN entegrasyon modelinde ve uygulanan yapıda veriler birbirinden çok farklı sistemlerde yer almasına rağmen, tek bir veri merkezinde bulunuyormuş gibi, merkezi bir yapidan veri sorgulaması gerçekleştirmektedir. Web servisleri ile erişimde, sorgulamalar ilgili veri kaynaklarına gönderilerek, elde edilen sorgu sonucu kullanıcıya sunulmaktadır. Web servislerinin yönlendirildiği DataOCEAN merkezi bilgi kontrol katmanı tasarlanırken hem hızlı veri girişi, hem de veriye hızlı ulaşım için uygulanması gereken kurallar korunmuştur.

DataOCEAN özellikleri;

- Entegrasyon yazılım katmanındadır.

- Merkezi veri erişimi sunmaktadır.

- Veri ve veri kaynaklarının yapısı ve türü özgündür.

- Platform bağımsızdır ve her sisteme entegre olabilmesi için bir arabirim kodlanmıştır.

Sistem için gerek koşul: modelde yer alan yapıların tamamının internet çıkışının olmasıdır. Platformdan bağımsız olduğu için bu anlamda bir kisıt söz konusu değildir. İkinci önemli gerek koşul ise; her veri için hazırlanan servisin web servisi standartlarını sağlayan yapıda olmasıdır.

Web servislerinin sistem kütüphanesine eklerken izlenen nesne tabanlı tanımlama mantığ1 ve algoritması bu çalışmanın kattı̆̆ 1 yeniliktir. Entegrasyon arabiriminde web servisi şeklinde sunulabilen her türden verinin birbiri ile entegre edilme olanağ 1 vardır. Veri sorgulama işlemi, sistemler birbirinin yapısını bilmek zorunda olmaksızın, yazılımsal bir ara katman aracılığı ile tek bir veri alanından veri sorgularmış gibi gerçekleşmektedir. Sistemler aras1 entegrasyon yazılım katmanında, yazılım arabirimi eklenerek sağlanmıştır.

DataOCEAN Bilgi Sistemi Modeli, SOA mimarisi üzerine kurulmuş, web'e çıkışı olan, her ortama uyarlanabilir, platform bağımsız, bir modeldir(Şekil 1).

\subsection{DataOCEAN Çalışma Mimarisi}

DataOCEAN'da kullanıcı, sistemde yer alan web servislerinin kaynakları ve yapılarıyla direkt ilişkili değildir. Ancak, sorgulama esnasında en doğru kabul edilen veriyi kullanacak şekilde tasarlanmıştır. Sistemde tanımlı olan web servisleri içerdikleri verilere ve yanıtlayacakları sorgu tiplerine göre tutulmaktadır. 
- Web servislerinin OceanLIBRARY(OLY) kütüphanesindeki tanımı, OOP Namespace (Object Oriented Programming Namespace) yapisin 1 anımsatan bir hiyerarşi güdülerek tanımlanmıştır.

- Sistem sunucularında kurulmuş olan DataOcean arabirimi, SQL (Structured Query Language) ile birbirine bağlanarak sorgulamay1 kolaylaştırmaktadır.

DataOCEAN modeli REST mimarisine göre dizayn edilmiş ve kodlanmış bir RESTful web servisi olarak çalışmaktadır. Sisteme gelen sorgu, sql cümleciğini alır ve işlendikten sonra JSON yapısında veri döndürür (Özdikililer, 2017).

\subsection{DataOCEAN WEB Servisleri}

DataOCEAN web servisi tanımlama alanında, Servis ekleme, Servis güncelleme, Servis silme ve Servis senkronizasyonu işlemleri yapılmaktadır. Web servis tanımları nesne yönelimli mimari yapısına uygun olarak yapılır. İlk servis tanımlamasından sonra servis yapısındaki değişikliklerde DataOCEAN'da kod olarak bir değişiklik gerekmemektedir. DataOCEAN modelinin en önemli katkılarından biri yazılım katmanında yapılan servis tanımlama mantığıdır. DataOCEAN yapisinda geleneksel URL okuma ve güncelleme işlemleri yapılması gerekmez. Birbirine bağlı DataOCEAN sunucuları birbirleri üzerindeki servis kütüphanelerini sürekli senkronize ederler.

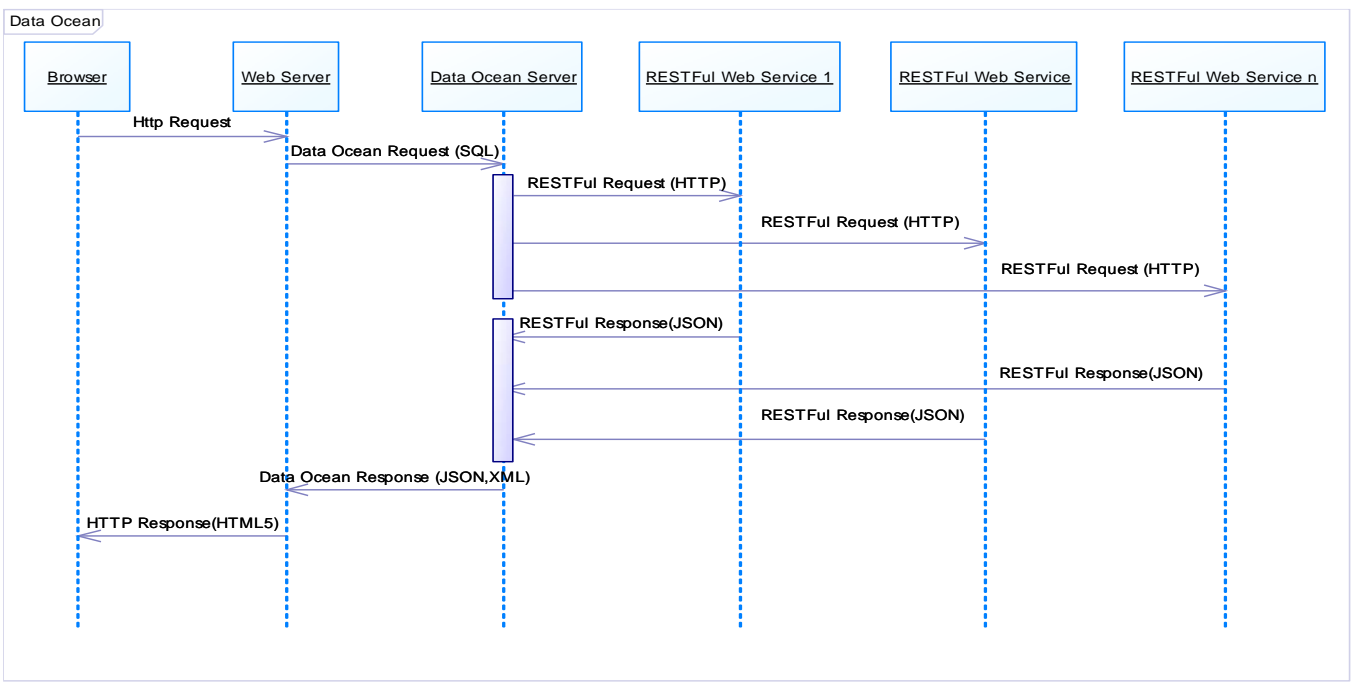

Şekil 1. DataOCEAN Sistem Modeli.

Değişen bir servis diğer sunucularda da güncellenmiş olur. Servis tanımının yer aldığ 1 JSON dosyas1, sistemde bulunan "webservices" dizininin içindeki alt dizinlere servisin isim uzay(namespace)'ının adlandırma sırasına göre yerleştirilmelidir. DataOCEAN da bulunan ADD Registry OLY kütüphanesine yeni web servisi eklenmesini sağlar. Gelen servis bilgisini okuduktan sonra, gelen servise özel JSON dosyasını oluşturur.

Her sistemin kullandığ temel web servisi KİMLİK olduğundan uygulamada da birincil servis olarak belirlenmiştir. Kimlik Bilgi Servisi ülkemizde yaygın olarak kullanılan Kimlik servisindeki yap1 kullanılarak hazırlanmıştır. Bütün servislerde kullanılan veriler gerçeğe uygun üretilmiştir.

DataOCEAN yapisinda demografik servislerin yanısıra konumsal servisler de yer almaktadır. Veri erişimi ve paylaşımı için birlikte çalışabilirlik ilkeleri esas alınarak çalışılması gerekmektedir. Birlikte çalışabilirlik altyapıları ve standartları tüm alanlarda vazgeçilmez olduğu gibi, konumsal veri ve konumsal servisler alanında da önemli bir gereksinimdir. Sistemin konumsal veri ekleme ve görselleştirme yeteneği de önemlidir. DataOCEAN Sisteminin adres konum servisi Google MAP'in kullandığ 1 GeoCode (Google) servisini kullanmaktadir. Servise gelen açık adres bilgisinin 
GoogleMAP GeoCode API'nnı kullanarak adresin enlem, boylam ve harita (map) adresini almaktadır. Bu konum bilgisi Google Map üzerinde noktasal olarak ifade edilmektedir.

\section{UYGULAMA}

İstanbul ilçelerinde planlanan kentsel dönüşüm çalışmaları ve bu kapsamda yeni yapilara olabilecek talep ve potansiyel alıc1 kitlesi belirlemek amaciyla çeşitli kurumlardan alınacak bilgilerin entegre edilerek bir tahmin sonucunun üretilmesi DataOCEAN uygulama konusu olarak seçilmiştir.

Son 5 yılda, İstanbul-Beşiktaş ilçesinde yapılan yeni yapılar, değişim ve dönüşüme uğrayan bölgeler, muhtemel konut fiyatları, kayıp ve artışlarıyla birlikte, mülk satışı değerleri, ilçe sakinlerinin ortalama gelir/gider bilgileri ile potansiyel alıc kitlesi belirleme çalışması planlanmıştır. Yapılan bu kurguda gerekli olan bilgiler: Yeni yapılar, konumları, bu konuma yakın ikamet eden kişiler, ilgili kişilerin banka bilgileri, önceden belirlenmiş hesap bakiyesi tutarı olanların kredi notu, tanıtımın yoğunlaşacağ 1 hedef kitlenin belirlenmesi vb. bilgilerdir. $\mathrm{Bu}$ prototip uygulamada kullanılan veriler gerçek veriler ve gerçek kimlikler olmayıp, gerçeğe uygun olarak üretilmişlerdir.

\section{1. Örnek Sorgulama Algoritması}

Illgili bölgelerde yaşayanların tespiti

- Harita üzerinden çalışılacak bölge seçilir.

- Seçilen alanda ikamet edilen kişilerin bilgisi alınır. Adres veri tabanından alınan anlık veri, uygulama aracılığ 1 ile üretilen tabloya aktarılır.

- Aktarilan tablodan TC Kimlik No elde edilir.

Kişilerin banka bilgisine erişilmesi.

- TC Kimlik No'lara WS_Banka servisi ile, belirlenmiş kriterler doğrultusunda sorgu oluşturulur, servise aktarılır, bilgilere ulaşı1ır, uygulama aracılığı ile Banka tablosuna/JSON dosyasina aktarılır.

Kredi notu tespiti

- Banka tablosundaki kişilerin WS_Kredi Notu servisiyle sorgulanır, veriler uygulama aracilığ 1 ile tabloya/JSON dosyasina aktarılır.

Operasyon

Bu kurguda toplam 4 web servisi kullanılmış, 3 ayrı tablo/JSON dosyası oluşturulmuştur. Mekansal sorgulama sonras1 elde edilen veri, referans harita kullanılarak görselleştirilmiştir (Şekil 3). 


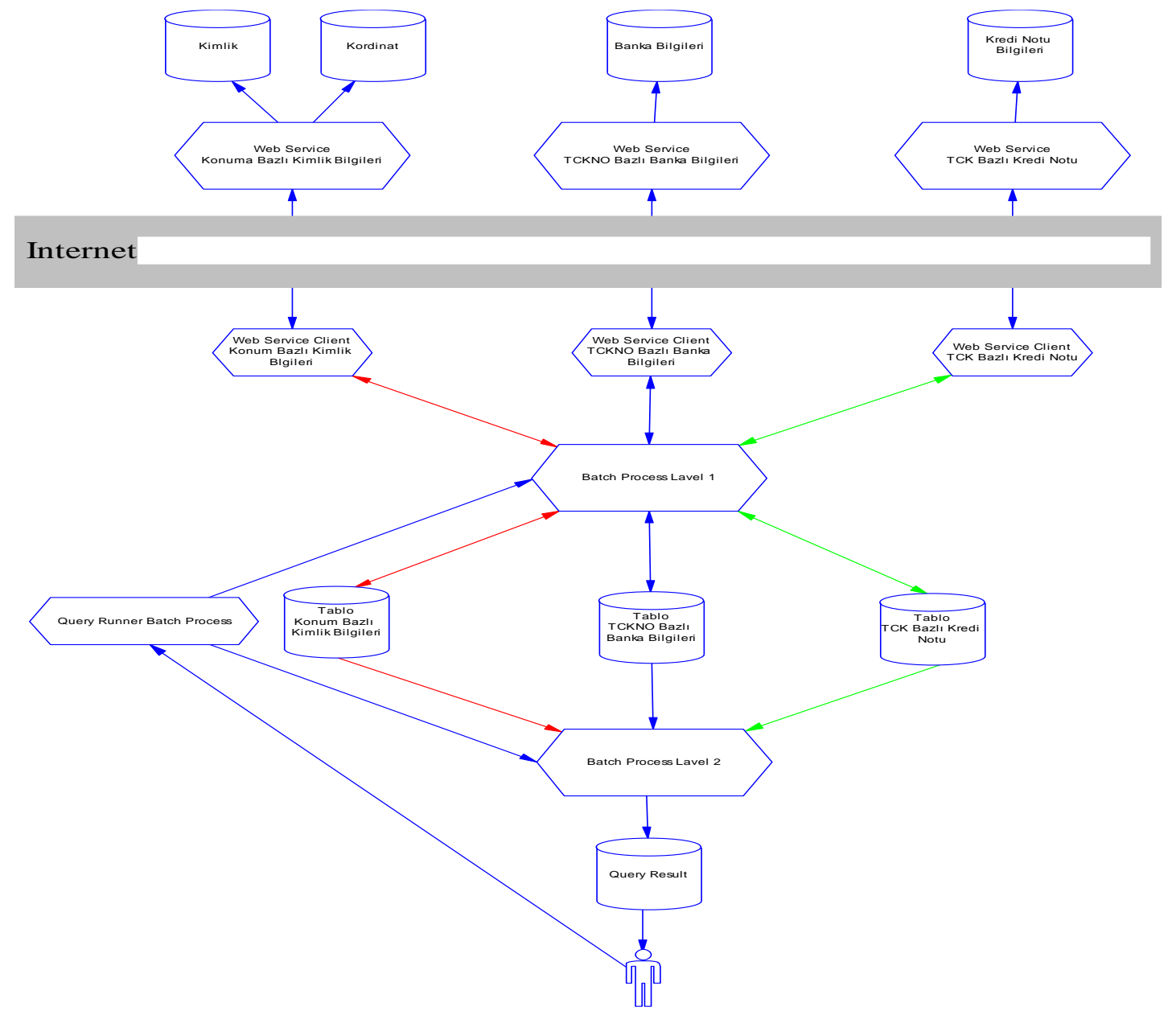

Şekil 2. DataOCEAN Uygulama Çalışma Mimarisi

Tasarlanan modelin şematik gösterimi Şekil 2'de yer almaktadır. İzlendiği gibi, web servisinin request objesi ile hangi elemanları sorgulanacak ise, yeni bir where couse yaratılmaktadır. Sisteme gelen istek sonras1 merkezi bilgi kontrol katmanında bulunan algoritma ile ulaşılacak web servisleri ve erişim sırası belirlenmektedir. Yapılan çalışmada kullanıcı talebi sonrasında oluşan ilgili girdi parametreleri DataOCEAN kontrol katmanı aracılığ 1 ile önceden belirlenmiş algoritma kullanılarak ilgili servislere yönlendirilmiş ve çalışma başlatılmıştır. Kullanılan web servisi sayıs1, servislerin aktarıldığ1 tablo yap1 ve sayıları talep edilen sonuç doğrultusunda tamamen dinamik olarak oluşturulmuştur.

Sorgulamada yönlendirilen sonuç bilgisi Google Map altlıklı haritada ve grid şeklinde yer almaktadır. Kullanılan toplam 4 servisten sorgulanan veri süresi 00:01:53 olarak görülmektedir.

\section{SONUÇLAR ve TARTIŞMA}

DataOCEAN sistem modeli SOA yapılarının entegrasyon süreçlerinde daha verimli kullanılması amacı ile tasarlanmış, prototip yazılım ve gerçeğe yakın kurgulanan uygulama çalışma ortamı ile birlikte sunulmuştur. 


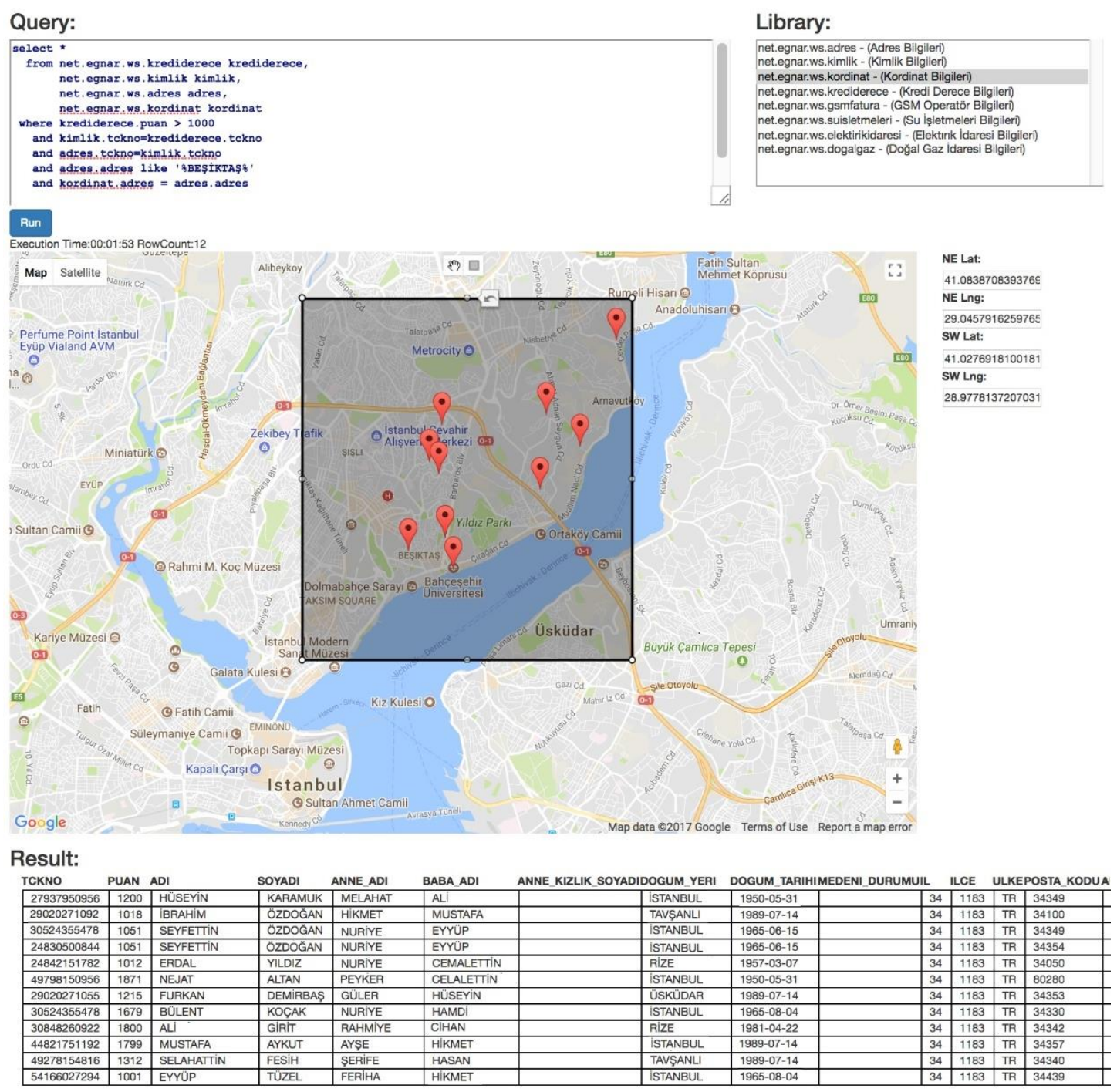

Şekil 3. DataOCEAN Sonuç Ekran Görüntüsü.

Modelin tasarım aşamasında belirlenen temel amaç sistemler arası entegrasyon işleminde iyileştirme ve yazılım hazırlama sürecini kısaltmaktır.

$\mathrm{Bu}$ çalışmada Web servisleri "birlikte çalışabilirlik" esasına uyularak standartlar çerçevesinde tasarlanmışlardır. Konumsal servislerde OGC yapıları esas alınmıştır. Çalışmadaki sonuçlar gerçeğe yakın ortam yaratılarak incelenmiş ve yorumlanmıştır. Konumsal veri bilgisi, gelen servislerde bulunmakla birlikte, veri boyutlarının büyük olacağı ön görülerek (örn. uydu görüntüleri), sistemin merkezi yapisinda da yer almaktadırlar.

SOA yapılarının entegrasyon süreçlerinde verimli kullanım olanaklarından yararlanılarak tasarlanmış olan DataOCEAN ile, SOA yapılarının entegrasyon süreçlerine dahil edilmemesi durumu için amaçlanan işlem için test çalışması yapılmıştır. DataOCEAN sistem modeli ile amaçlanan işlemin kısa sürede hızlı ve doğru olarak yapıldığı tesbit edilmiştir.

Web servislerin doğruluk derece değerleri, servisleri OceanLibrary kütüphanesine tanımlama aşamasında bir kabul doğrultusunda belirlenerek eklenmektedir. Eklenen web servisinin doğruluğu ham veriyi servis veritabanına ekleyen kurumun güvenilirliği doğrultusunda kararlaştırılmaktadır.

$\mathrm{Bu}$ çalışmanın özgün katkılarından biri: yazılım katmanında yapılan servis tanımlama algoritmasidır. DataOCEAN yapısında URL okuma ve güncelleme işlemlerinin yapılması gerekmeksizin DataOCEAN sunucuları 
değişiklik durumunda (ekleme, çıkarma, düzenleme) servis kütüphanelerini senkronize etmektedir. Sisteme entegre olan yapılar birbiri ile senkronizedirler.

Yazılım ölçütleri, tasarım ve kodun anlaşılabilirliği, kodlama kolaylığı, hızı, maliyet, üretim zamanı, bakım ve kullanım kolaylığı süreci açısından değerlendirmeleri içermektedir. Tasarım sonrası, programlama döneminde, henüz yazılım çalıştırılmadan, sadece kaynak kodu incelemek için kullanılan statik metrikler ve yazılımın çalışması sirasinda toplanan verilerden elde edilen dinamik metrikler değerlendirilmiştir. DataOCEAN modeli ve yazılımda yer alan nesneler, sınıflar ile aralarındaki ilişkiler, ilişkilerin yapısal özellikleri nesne yönelimli tasarım metrikleri kullanılarak değerlendirilmiştir. $\mathrm{Bu}$ bağlamda, $\mathrm{Php}$ Metrics'den üretilen raporda (Lepine, 2017): uygulamanın az satır sayısı ile gerçekleştirildiği, kod satır sayısı ile yapılan işlem orantısı karşılaştırıldığında, yazılım açısından başarılı olarak değerlendirildiği, sınıflar arasındaki etkileşim kabul edilebilir, hatta, iyi sayllabilecek normlar içerisinde olduğu sonuçları belirtilmiştir. Kod karmaşıklığı açısından bazı noktalar için erişim konusunun incelemeye tabi tutulması gerektiği ve yazılan sınıfların tespitinin karmaşık olduğu belirlenmiştir. Tasarım birden fazla mimariyi esas aldığından, kompleks bir yapıya sahiptir ve yazılım tarafından karmaşık kabul edilmesi beklenilen bir sonuçtur.

$\begin{array}{llr}\text { DataOCEAN } & \text { dinamik } & \text { metriklerin } \\ \text { değerlendirmesi } & \text { sonucunda; } & \text { metotların }\end{array}$ sayısının az olduğu, fakat karmaşıklığının da sınıfın geliştirilmesine ve bakımına harcanacak zaman-çaba oranını kabul edilebilir sınırlar içerisinde bıraktığı raporlanmıştır.

DataOCEAN sisteminde, bilginin bilgisi, birbiri ile ayr1 ayrı birer sistem olup, efektif kullanılan yapıların entegrasyonunda, anlık veri erişiminin yanısıra güncelleme de aynı doğruluk ve hız çerçevesinde yapılmaktadır. Gelecek çalışmalarda, anlık sorgulanan verinin veritabanına eklenmesi ile ilgili bir algoritma katkısı ile DataOCEAN, uzun vadede mükerrer veri kaydı içermeyen arşiv verisi de oluşturabilecek bir uygulamadır. Hızlı veri paylaşımına uygun mimarisi ile servis odaklı ve zamana bağl1 bir model olarak son kullanıcının hizmetine sunulmuştur.

\section{TEŞEKKÜR}

Bu çalı̧̧ma, ITÜ Bilişim Enstitüsü Uydu Haberleşmesi ve Uzaktan Algilama Programinda tamamlanmış olan "Entegre Bilgi Sistemi Modeli Geliştirilmesi:DataOCEAN" başlıklı tezden üretilmiştir. Doktora çalışmasını destekleyen ITÜ Bilimsel Araştırmalar Proje Birimine çalışma için sunduklarl olanak ve katkular için teşekkür ederiz.

\section{KAYNAKCA}

Al-Kiswany, S., et al., A cross-layer optimized storage system for workflow applications. Future Generation Computer Systems, 2017. 75: p. 423-437.

Bahree, A., et al., Pro WCF: practical Microsoft SOA implementation. 2007: Apress.

Fielding, R.T., Architectural styles and the design of network-based software architectures. 2000, University of California, Irvine.

Glatard, T., et al., Software architectures to integrate workflow engines in science gateways. Future Generation Computer Systems, 2017. 75: p. 239-255.

Ghadiri, N., M. Ghaffari, and M.A. Nikbakht, BigFCM: Fast, precise and scalable FCM on hadoop. Future Generation Computer Systems, 2017. 77: p. 29-39.

Google,https://developers.google.com/maps/docum entation/geocoding/intro, available in 11.03.2018

Krafzig, D., K. Banke, and D. Slama, Enterprise SOA: service-oriented architecture best practices. 2005: Prentice Hall Professional

Lepine, J.-F. Metrics for PHP. 2017 (cited 2017 14.11.2017); Jean-Françoia Lepine).

Available from: http://www.phpmetrics.org//documentation index.html.

Özdikililer, E. (2017). Doktora Tezi, İTÜ Bilișim Enstitüsü, İstanbul, Türkiye. Entegre Bilgi Sistemi Modeli Geliştirilmesi: DataOCEAN@

Söderström, E. and F. Meier, Combined SOA maturity model (CSOAMM): Towards a guide for SOA adoption, in Enterprise Interoperability II. 2007. Springer. p. 389400. 